\section{Minimally invasive surgery}

\section{May disseminate undiagnosed tumour}

EdrToR,-R C G Russell's article on laparoscopic cholecystectomy is comprehensive but fails to mention an important aspect of the operationnamely, the problems that arise if an inapparent carcinoma of the gall bladder is removed laparoscopically. ${ }^{1}$ Several cases of tumour seeding at the site through which the gall bladder was removed have been reported, ${ }^{23}$ as well as cases of widespread intraperitoneal metastases developing postoperatively. ${ }^{4}$ We have also seen such a case: a patient who had an inapparent pT1 (pathological tumour grade 1) removed laparoscopically later developed metastasis of the abdominal wall. A potentially curable tumour was therefore upgraded; the patient later died.

Shiria $e t$ al found that mortality was decreased when patients who had had early carcinomas of the gall bladder removed at open operation underwen a second, radical operation. ${ }^{5}$ Those with more advanced tumours had an improved disease free survival.

The incidence of carcinoma of the gall bladder detected histologically after cholecystectomy is reported as $1-2 \%$. With laparoscopic cholecystectomy, tumour seeding will be more widely encountered and should therefore be addressed in discussions of the technique. Simple methods such as avoiding aspiration of the gall bladder at laparoscopy and placing the organ in an impermeable bag before removal should be considered, as should further open radical surgery or chemotherapy when the problem has been recognised.

RICHARD C JOHNSON LOUIS J FLIGELSTONE

Department of Surgery,

University of Wales College of Medicine,

Cardiff CF4 4XN

Department of Clinical Oncology,

Velindre Hospital,

Cardiff CF4 6XB

1 Russell RCG. General surgery: biliary surgery. $B M$ 1993;307:1266-9. (13 November)

2 Drouard F, Delamarre J, Capron J-P. Cutaneous seeding of gallbladder carcinoma after laparoscopic cholecystectomy. $N$ Engl F Med 1991;325:316.

3 Clair GC, Lautz DB, Brooks DC. Rapid development of umbilical metastases after laparoscopic cholecystectomy for unsuspected gallbladder carcinoma. Surgery 1993;113:355-7.

4 Pezet D, Fondrinier E, Rotman N, Guy L, Lemesle P, Lointie $P$, et al. Parietal seeding of carcinoma of the gallbladder after laparoscopic cholecystectomy. Br I Surg 1992;79:230.

5 Shiria Y, Yoshida K, Tsukada K, Muto T. Inapparent carcinoma of the gallbladder: an appraisal of a radical second operation after simple cholecystectomy. Ann Surg 1992;215:326-31.

\section{Bile leak risk after laparoscopic cholecystectomy}

EDrToR,-I was interested in the account of laparoscopic cholecystectomy by R C G Russell.' Complications of retained intraperitoneal calculi and biliary leak seem to be more common after laparoscopic than open cholecystectomy. ${ }^{23}$

A 40 year old woman who suffered from biliary colic in July 1992 was found to have a gall bladder full of stones. She was admitted for laparoscopic cholecystectomy in September 1993. At operation the gall bladder was packed with calculi and difficult to grasp. A small cystic duct was clipped and the gall bladder removed with difficulty; a few stones were left in the abdomen. The patient was discharged after 48 hours.

Four days later she was readmitted with abdominal pain, distension, and vomiting. Plain radiography showed generalised ileus. Ultrasound examination showed bilomas in the subhepatic region and pelvis mimicking stones in the urinary bladder (figure). She had a polymorphonuclear leucocytosis with a white cell count of $16000 / 1$ and a low serum potassium concentration but otherwise normal biochemical variables.

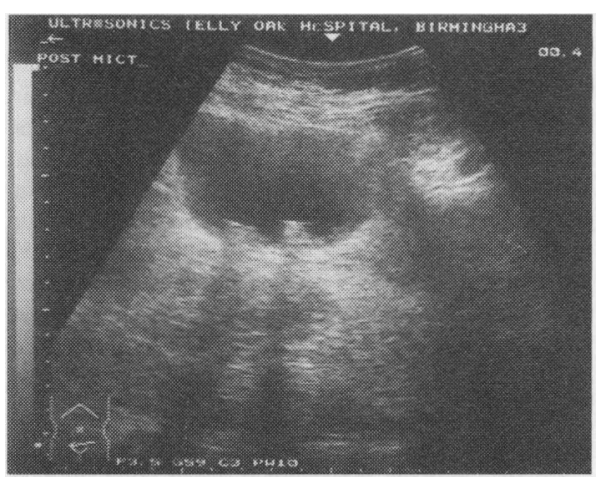

Transverse ultrasound scan showing stones in biloma

She was treated conservatively and responded well, only to deteriorate again after five days of admission. A repeat scan showed increased intraperitoneal fluid. At emergency laparotomy over 4 litres of bile was drained and stones were removed from the subhepatic region and pelvis. The gall bladder bed was found to be sealed off by omentum. The cystic artery and cystic duct clips were intact, so most of the leak probably occurred from the gall bladder bed. The postoperative period was uneventful, and the patient was discharged after 10 days.

Biliary tract complications of laparoscopic cholecystectomy tend to occur two to eight days afterwards, common symptoms being abdominal pain, vomiting, and distension. Most bile leaks are restricted to the gall bladder bed and perihepatic region; retained calculi may or may not be present. Laparascopic cholecystectomy shortens the hospital stay, and patients can return to normal activity within a few days. When a leak is suspected radiological input is helpful to plan for appropriate treatment.

I thank Mr D J Campbell, consultant surgeon, for permission to report this case.

VR KALE

Department of Diagnostic Imaging

Selly Oak Hospital

Birmingham B29 6JD

1 Russell RCG. General surgery: biliary surgery. BMF 1993;307: 1266-9. (13 November.)

Walker AT, Shapiro AW, Brooks DC, Braver JM, Tumeh SS. Bile duct disruption and biloma after laparoscopic choleBile duct disruption and biloma after lapar

cystectomy. Am f Roentgenol 1992;158:785-9.

Walshaw CF, Deans H, Krukowski ZH. Free intraperitoneal gal stones following laparoscopic cholecystectomy. Clin Radiol 1993;48:258-9.

\section{No benefit in hernia repair ...}

EdrTor,-In his review of minimally invasive procedures in abdominal surgery John R T Monson described procedures that have gained acceptance, but some procedures are still experimental and controversial. An example is laparoscopic repair of an inguinal hernia, which has been promoted as less painful than conventional open repair, with a shorter stay in hospital and a shorter recovery period. Both procedures are suitable for day case surgery.

Laparoscopic repair of an inguinal hernia requires general anaesthesia, whereas open repair can be done with local anaesthesia combined with sedation. As far as pain is concerned, it is questionable whether laparoscopic repair is overwhelmingly superior. With pre-emptive analgesia, use of a "tension free" mesh and administration of a non-steroidal anti-inflammatory drug results in minimal postoperative discomfort, and a return to full activity is possible within days. ${ }^{2}$ If given a choice most patients prefer local anaesthesia.

Laparoscopic repair of an inguinal hernia converts an intermediate procedure into a major one and exposes patients to the inherent risks of laparoscopy. The deep general anaesthesia and pneumoperitoneum may adversely affect cardiovascular and pulmonary function. Surgical hazards include gas embolism and injury to abdominal viscera and vessels.

The transperitoneal approach to the inguinofemoral region traumatises a large peritoneal surface area and, with the mesh reconstruction, creates conditions ideal for adhesive bowel obstruction. This complication was found to have a high incidence (up to $35 \%$ ) in an experimental trial of laparoscopic repair of an inguinal hernia in pigs. ${ }^{3}$ Acute intestinal obstruction has been reported after laparoscopic repair, ${ }^{4}$ and may prove to be a long term problem.

Cost is an important factor. Laparoscopic repair of an inguinal hernia is more expensive than open repair, requiring general anaesthesia, a longer operating time (1-3 hours), and disposable items costing $£ 300$. Open repair with local anaesthesia and sedation takes less than 45 minutes, and the drugs and disposables cost about $£ 35$.

The disadvantages of laparoscopic repair of an inguinal hernia and the benefits of open repair with local anaesthesia and sedation are so obvious that justifying the laparoscopic procedure is hard. If comparative trials are needed the laparoscopic procedure should be limited to a few centres. Instead of resources being wasted on the laparoscopic procedure, greater emphasis should be placed on training in the open procedure with local anaesthesia and sedation.

M J NOTARAS

Barnet General Hospital,

Wellhouse Trust,

Barnet EN5 3DJ

1 Monson JRT. Advanced techniques in abdominal surgery. $B M$ 1993;307:1346-50. (20 November.)

2 Lichtenstein IL, Shulman AG, Parviz KA, Montillor MM. The tension-free hernoplasty. Am f Surg 1989;157:188-93.

3 Crist D, Gadacz T. Complications of laparoscopic surgery. Surg Clin Norh Am 1993;73:265-89.

4 Hendrickse CW, Evans DS. Intestinal obstruction following

laparoscopic inguinal hernia repair. $B r f$ Surg 1993;80:1432.

\section{...or appendicectomy}

EDrTOR,-In his article on advanced techniques in abdominal surgery John $\mathbf{R}$ T Monson suggests that laparoscopic surgery has several advantages over open procedures, including a reduced incidence of wound infection, reduced postoperative pain, earlier mobilisation, and an earlier return to normal activity. ${ }^{1}$ Attractive though this may seem, 